\title{
Establishment of a Micropropagation Protocol for Elite Accessions of Bael (Aegle marmelos (L.) Corr.), a Tropical Hardwood Species
}

\author{
Chamila Pathirana $\mathbb{D D}^{1,2}$ Udayanthi Attanayake, ${ }^{1}$ Udula Dissanayake, ${ }^{1}$ \\ Lakshman Gamlath, ${ }^{3}$ Kalyani Ketipearachchi, ${ }^{3}$ Terrence Madhujith, ${ }^{2,4}$ \\ and Janakie Eeswara ${ }^{1,2}$ \\ ${ }^{1}$ Department of Crop Science, Faculty of Agriculture, University of Peradeniya, Peradeniya 20400, Sri Lanka \\ ${ }^{2}$ Postgraduate Institute of Agriculture, University of Peradeniya, Peradeniya 20400, Sri Lanka \\ ${ }^{3}$ Fruit Crop Research \& Development Station, Gannoruwa, Peradeniya, Sri Lanka \\ ${ }^{4}$ Department of Food Science and Technology, Faculty of Agriculture, University of Peradeniya, Peradeniya 20400, Sri Lanka
}

Correspondence should be addressed to Chamila Pathirana; ckpathirana0421@gmail.com

Received 20 April 2020; Revised 16 July 2020; Accepted 9 September 2020; Published 22 September 2020

Academic Editor: Gábor Kocsy

Copyright (c) 2020 Chamila Pathirana et al. This is an open access article distributed under the Creative Commons Attribution License, which permits unrestricted use, distribution, and reproduction in any medium, provided the original work is properly cited.

The limited availability of high-quality planting material hinders the popularization of bael (Aegle marmelos (L.) Corr.) as a profitable cash crop in Sri Lanka. Five elite bael accessions, namely, Beheth Beli, Paragammana, Mawanella, Rambukkana, and Polonnaruwa-Supun, have been identified and used for mass propagation through budding and grafting. However, this process gets hampered by the limitations in large-scale production of planting material. Micropropagation is an alternative technique to produce clonal plants in large-scale; however, no established protocol is available for the field-grown elite bael accessions in Sri Lanka, and hence, the present study was conducted. The best sterilization method was found to be the washing of explants in a $2.5 \%$ fungicide solution for two hours. The full MS and $1 \frac{2}{2}$ SS media provided significantly similar performance in shooting, as indicated by the measured parameters. The twig plants did better than leaf explants concerning shoot extension, in which twig explants yield $1.33 \mathrm{~cm}$ taller shoots. The $1 \mathrm{mg} / \mathrm{l}$ of BAP concentration generated the highest number of shoots (6.20) and the most extended shoots $(3.83 \mathrm{~cm})$. The most successful rooting $(60 \%$ success) was spotted with full MS, $1 \mathrm{mg} / \mathrm{ml} \mathrm{NAA}$, and $3 \%$ sugar. As previously reported, the successful micropropagation is possible if the explants are harvested from April to June, immediately after the fruiting season of the plant. The established protocol can mass-produce clonal bael plants from the elite accessions.

\section{Introduction}

Aegle marmelos (L.) Corr. of family Rutaceae, commonly known as bael, is a medicinal fruit tree fruit species [1]. Bael is native to India and found in other South Asian countries such as Sri Lanka and Bangladesh, Southeast Asia, and Egypt [2]. The ripened fruit is the economically important plant part of bael, and all the plant parts have essential medicinal properties $[3,4]$. The pulp of the ripened fruits is delicious and can also be processed into value-added products such as jam, syrup, sweets, and herbal drinks [5,6]. Bael is considered as a sacred tree in India and often grown near the temples dedicated to 'God Shiva' [2]. The fruits and other plant parts of bael contain essential phytochemicals such as tannin, coumarin, aegelinol, and marmelocin, and they exhibit various medicinal properties ranging from laxative, antiproliferative, antidiabetic, and anticancerous capabilities $[7,8]$.

Bael is a well-established medicinal fruit tree species, and the selections from the wild germplasm have led to larger fruit sizes and superior fruit qualities. The elite bael plants have been identified, and attempts have been made to multiply them for large-scale cultivations in India [9]. However, the propagation using seeds is often hampered by 
the extreme genetic heterozygosity due to open pollination, lower seed germination rates, and difficulty in collecting and processing seeds from mature fruits. Furthermore, it is challenging to produce a large amount of planting material through budding and grafting techniques. Thus, plant tissue culture techniques can be used as an alternative to overcome problems associated with the multiplication of superior trees identified in the wild/field. Micropropagation techniques have been successfully employed for rapid multiplication of the superior bael plants using cotyledons [10-13], nodes [9], and the axillary buds $[14,15]$. However, it is essential to develop a micropropagation protocol for the explants collected directly from the mother plants growing in the field to multiply the bael accessions. The establishment of cultures without contamination is one of the major problems when explants are collected from field-grown trees [16]. Thus, the development of a specific sterilization technique for plant materials obtained from the field is an essential requirement before identifying the growth stage for the collection of plant materials and perfecting the medium composition for multiplication of plants. Therefore, the present study was conducted to develop a protocol for multiplication of bael from plant materials collected from trees identified as accessions by the Fruit Research and Development Station (FCRDS) at Gannoruwa, Sri Lanka.

\section{Materials and Methods}

2.1. Plant Material. Five Sri Lankan bael accessions, namely, Beheth Beli (BB), Paragammana (PA), Mawanella (MA), Rambukkana (RA), and Polonnaruwa-Supun (PS), which have been selected for large-scale production of planting materials, were used to collect the explants for developing a protocol for micropropagation. Leaves and twigs were used as the explants. The study was conducted at the Tissue Culture Laboratory of the Department of Crop Science, Faculty of Agriculture, University of Peradeniya, Sri Lanka. The explants from the mother plant of $\mathrm{BB}$ were collected from FCRDS (GPS coordinates: 7.277006, 80.595299) during the vegetative growth stage (April-June, 2018) [17]. All the investigations on sterilization and identification of the specific growth stage for culture establishment were conducted using BB mother plants. Then, the results achieved were applied to other four accessions when they were at the same vegetative growth stage, which are located at distant locations from the study site.

\subsection{Experiment 1: Effect of Fungicide on Surface Sterilization of Twig and Leaf Explants}

2.2.1. Preparation and Washing of Explants. The disease-free immature leaves and tender twigs were collected from top parts of the branches of each mother plant and immediately transferred to the laboratory for micropropagation. The dried/dead and infected portions were removed from the intended explants. The twigs and leaves were isolated, and the twigs containing at least three to four internodes were used for culturing. The leaves and twig explants were thoroughly cleaned using a commercially available detergent mixture and smooth bristles. The explants were rinsed using running tap water for $10-15$ mins. After washing three to four times, the plant parts were soaked in distilled water approximately for one hour. Then, subsequent steps were followed for further sterilization to avoid the bacterial and fungal infections.

2.2.2. Fungicide Treatment. The plant parts were soaked in a series of fungicide (commercial formulation thiram with the active ingredient dimethyldithiocarbamate $\left(\mathrm{C}_{6} \mathrm{H}_{12} \mathrm{~N}_{2} \mathrm{~S}_{4}\right)$ ) solutions $(0.5 \%, 1.0 \%, 1.5 \%, 2.0 \%$, and $2.5 \%)$. At each concentration of fungicide, the plant parts were subjected to different exposure times ( $1 \mathrm{hr}, 2 \mathrm{hr}$, and overnight).

2.2.3. Surface Sterilization. The plant parts were washed carefully with distilled water to remove the fungicides. After that surface sterilization was performed for the explants. The leaf explants were transferred into a wash bottle, which consisted of $10 \%$ Clorox (sodium hypochlorite $(\mathrm{NaOCl})$ ) and a drop $(1 \mathrm{ml})$ of polyethylene glycol sorbitan monolaurate (Tween 20 (T20)) and shaken for $10 \mathrm{~min}$. Then, bleach solution was drained off and washed three times carefully with autoclaved water. That step was repeated with only $10 \% \mathrm{NaOCl}$, and cleaned plant parts were transferred to a vessel containing distilled water. The nodal segments and shoot tips (i.e., twigs) were surface-sterilized separately using $10 \%$ of Clorox along with two drops of Tween 20. The shaking was continued for ten minutes. Then, the twigs were transferred to a $10 \% \mathrm{NaOCl}$ solution without Tween 20 and were shaken well for another 10 mins followed by thorough washing (three times) with sterile, deionized, distilled water to wash off the traces of bleach solution. Each washing process lasted for approximately one minute.

2.2.4. Culture Establishment. All tissue culture techniques were conducted under aseptic conditions in a laminar flow cabinet (Labgard Class II, Type A/B3). The leaf and twig explants were prepared by trimming the cut surfaces to about $12-15 \mathrm{~mm}$ in length. The MS [18] medium supplemented with $1 \mathrm{mg} / \mathrm{l}$ of BAP, $3 \%(w / v)$ of sucrose, and solidified with $0.2 \%(w / v)$ Phytagel (Sigma, UK) was used as the medium based on the results obtained for nodal segments collected from in vitro grown seedlings in the tissue culture laboratory of the Department of Crop Science. The $\mathrm{pH}$ of the medium was adjusted to 5.8 with $1 \mathrm{M} \mathrm{HCl}$ or $\mathrm{NaOH}$ before autoclaving at $120^{\circ} \mathrm{C}$ for 20 mins, $15 \mathrm{psi}$. This medium was used for initiating the cultures. Each culture tube contained $10 \mathrm{ml}$ of medium. The inoculation was performed as one explant per culture tube. The leaf pieces at the size $1 \mathrm{~cm}^{2}$ (approximately) holding the midribs were isolated and placed on the medium. A gentle press was applied to have an even contact between the abaxial (lower) surface of the leaf and the medium. The single nodal twigs were inserted into the medium in the upright position. The leaf cultures were incubated inside a dark cabinet at $26 \pm 2^{\circ} \mathrm{C}$ until initiating the shoots. The twig cultures were incubated at $16 \mathrm{hrs}$ of light (flux density) at $25 \pm 2^{\circ} \mathrm{C}$. 
2.2.5. Scanning Electron Microscopy to Detect the Presence of Fungi in Leaf and Twig Explants. The fungicide-treated (2.5\%) and untreated leaf explants were subjected to scanning electron microscopy (SEM) to visualize the effect on fungicide treatment on the fungi present on explants. The leaves and twigs were taken and soaked in the fungicide solution for two hours. After that, they were cut into explant size pieces. The explants were then sprayed with gold particles for staining purpose and observed using the ZEISS scanning electron microscope (SEM) (Jeol SEM 6400, Tokyo, Japan). The SEM photographs were taken from the representative places of the explants.

\subsection{Experiment 2: Effect of $N$ Content in Medium on In Vitro} Multiplication. The effect of $\mathrm{N}$ content on the successful establishment of the cultures was assessed. To detect the effect of N, full MS and half MS media were prepared. The parameters such as the number of leaves/shoot, number of shoots/cutting, and height of the shoot were measured after eight weeks of establishment and statistically analyzed using the GLM procedure in the Statistical Package SAS 9.4 (SAS Institute, NC, Cary, USA).

2.4. Experiment 3: Effect of BAP Concentration on Multiplication of Regenerated Shoots. The effect of five BAP concentrations $(0.0,0.5,1.0,2.0$, and $4.0 \mathrm{mg} / \mathrm{l})$ on shoot multiplication was investigated. The subculturing was performed at every eight-week intervals. Each proliferated adventitious shoot was cut from the basal end and subcultured again for further multiple shoot induction. At the end of the 20th week onwards, regenerated multiple shoots were cut, and the shoots were transferred on to an MS medium without any plant growth regulators before transferring into a rooting medium. The number of shoots per explant and the length of the shoots were measured and subjected to GLM procedure in SAS.

2.5. Experiment 4: Effect of $N$, Sucrose, IBA, and NAA Concentration on Rooting. The effects of $\mathrm{N}$ (full and $1 / 2 \mathrm{MS}$ ), sucrose concentration (3\% and 6\%), naphthalene acetic acid (NAA) $(1 \mathrm{mg} / \mathrm{L})$, and indole-3-butyric acid (IBA) $(1 \mathrm{mg} / \mathrm{L})$ on rooting of micropropagated shoots were investigated. The experiment was arranged as a three-factor factorial experiment.

\subsection{Experiment 5: Acclimatization of In Vitro-Generated} Plantlets. The in vitro rooted plants were maintained in jars with ventilation for a month and after that transferred to small plastic pots $(10 \mathrm{~cm}$ in diameter) containing a standard potting mixture and allowed to grow in a greenhouse. The plants were covered with polyethylene sheets to maintain the relative humidity. The artificial lights were provided to have $70 \%$ light intensity. The covers were intermittently removed after one week every day and completely removed after two weeks. After four weeks, the survival percentage was calculated.

\section{Results}

3.1. Experiment 1: Effect of Fungicide on Surface Sterilization. The $2.5 \%$ fungicide solution in which explants were immersed for two hours produced the only successful regeneration. When the leaf and twig explants were subjected to $2.5 \%$ fungicide for two hours of treatment and subsequently cultured in $1 \mathrm{mg} / \mathrm{l} \mathrm{BAP}$ culture, initially till the fourth week, substantial amounts of contaminated and few browned cultures were observed. However, eventually, nearly $60 \%$ of cultures of both leaf and twig explants survived as healthy cultures after 5-6 weeks of establishment.

3.2. Effect of Fungicide Treatment on Fungi Present on Explants. The fungal hyphae were observed in upper (Figure 1(a)) and lower (Figure 1(b)) surfaces of the leaf explants. The fungicide treatment destroyed the fungal hyphae observed in the upper (Figure 1(c)) and bottom surfaces (Figure 1(d)). The sunken stomata were clearly visible in both upper and lower surfaces of the leaves (Figures 1(a)-1(d)). In the twig explants under 1000 and 5000 magnifications, fungal hyphae were not observed in untreated cases (Figures 1(e) and 1(g), respectively). The similar appearance was photographed for treated explants under the two magnifications (Figures $1(\mathrm{f})$ and $1(\mathrm{~h})$ ). Compared to the stomata in leaves, the stomata in twigs are smaller in size (Figures $1(\mathrm{e})-1(\mathrm{~h})$ ).

\subsection{Experiment 2: Effect of $N$ Content in the Medium on In} Vitro Multiplication of Regenerated Shoots. The mean number of shoots per cutting and the mean number of leaves per shoot were not significantly different among the two medium compositions and the type of explant $(P>0.05)$. However, the mean height of the shoot was significantly higher in twig explants than the leaf explants $(P<0.05)$ (Table 1). Two culture jars of full MS and $1 / 2 \mathrm{MS}$ are shown in Figure 2 to display the growth differences.

\subsection{Experiment 3: Effect of BAP Concentration on Multipli-} cation of Regenerated Shoots. The BAP level of $4 \mathrm{mg} / \mathrm{L}$ caused vitrification of shoots even after subculturing (Figures 3(a) and $3(\mathrm{~b})$ ). The BAP concentration of $1.0 \mathrm{mg} / \mathrm{L}$ provided the highest success. The mean highest number of shoots was observed for the BAP levels of $0.5,1.0$, and $2.0 \mathrm{mg} / \mathrm{l}$ (5.60-6.20). At the BAP level of 4.0, the mean number of 3.40 shoots was observed, and only two shoots were observed when no BAP was added. The mean shoot length was significantly different among all the BAP treatments. The significantly mean highest shoot length was observed at the BAP level of $1.0 \mathrm{mg} / \mathrm{L}(3.83 \mathrm{~cm})$, whereas the mean lowest shoot length was observed when no BAP was added $(2.49 \mathrm{~cm})$ $(P<0.05)$ (Table 2$)$. The shoots generated by BAP treatments other than the $4 \mathrm{mg} / \mathrm{L}$ concentration are displayed in Figure 4.

3.5. Experiment 4: Effect of $N$, Sucrose, IBA, and NAA Concentrations on Rooting. Table 3 displays the series of results obtained for the rooting experiments by altering $\mathrm{N}$ (MS or 

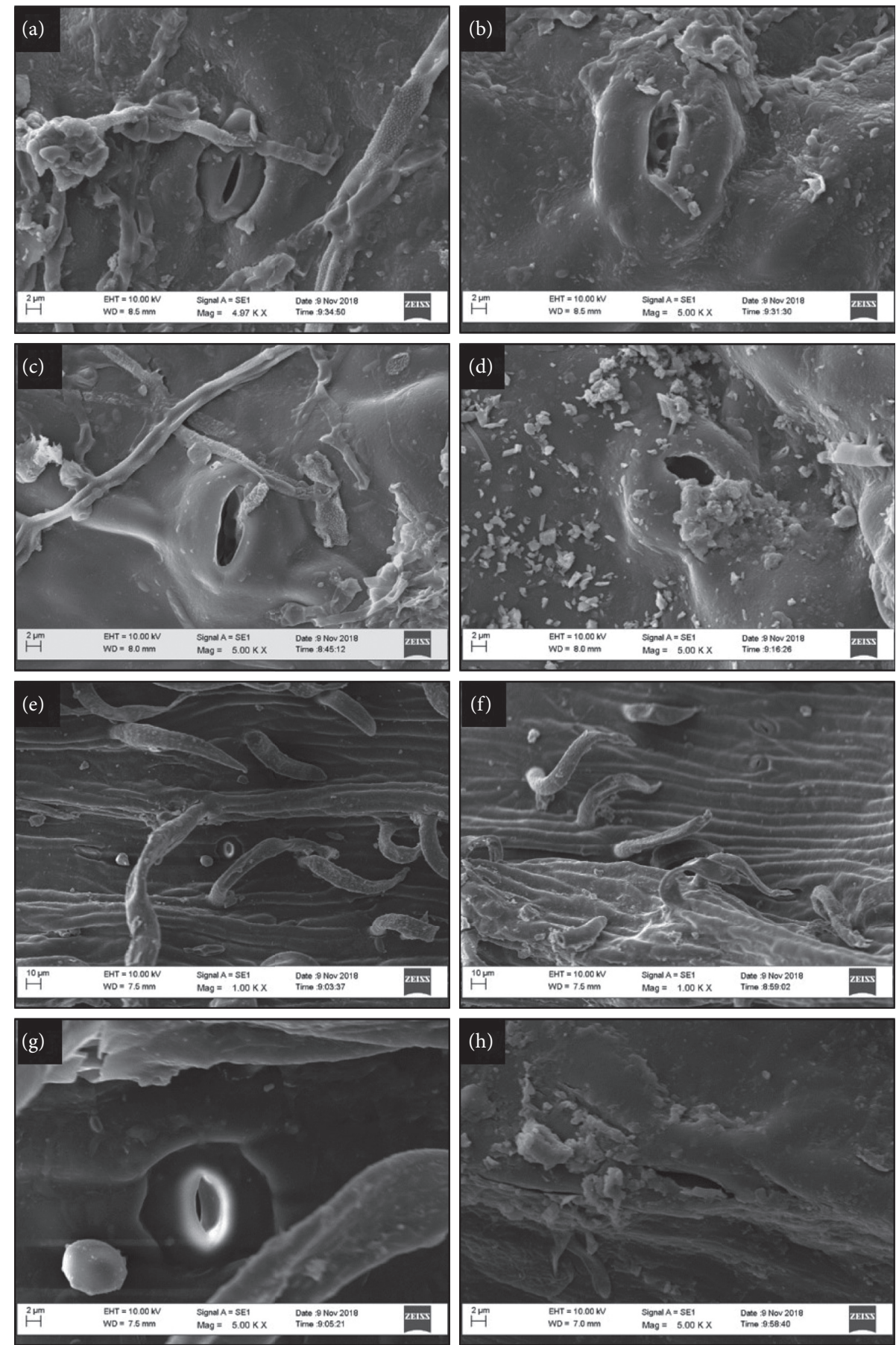

FIGURE 1: Scanning electron microscopy photographs of the leaf and twig explants (untreated and treated with fungicide). (a) Upper surface of leaves untreated; (b) upper surface of leaves treated; (c) lower surface of leaves untreated; (d) lower surface of leaves treated; (e) twig untreated $(\times 1000)$; (f) twig treated $(\times 1000)$; $(\mathrm{g})$ twig untreated $(\times 5000) ;(\mathrm{h})$ twig treated $(\times 5000)$. The specific details of each photograph are marked as a label with each photograph.

TABLE 1: The mean performance of the shoots under full MS and $1 / 2 \mathrm{MS}(\mathrm{N})$ conditions.

\begin{tabular}{lcccc}
\hline Medium & Type of explant & No. of shoots/cutting & Height of the shoot (cm) & No. of leaves/shoot \\
\hline \multirow{2}{*}{ Full MS } & Leaf & $7.40^{\mathrm{a}}$ & $2.27^{\mathrm{b}}$ & $3.67^{\mathrm{a}}$ \\
& Twig & $7.25^{\mathrm{a}}$ & $3.25^{\mathrm{a}}$ & $6.53^{\mathrm{a}}$ \\
\hline \multirow{2}{*}{$1 / 2 \mathrm{MS}$} & Leaf & $6.80^{\mathrm{a}}$ & $1.93^{\mathrm{b}}$ & $4.33^{\mathrm{a}}$ \\
& Twig & $6.50^{\mathrm{a}}$ & $3.60^{\mathrm{a}}$ & $5.57^{\mathrm{a}}$ \\
\hline
\end{tabular}

Means denoted by the same letters within columns are not significantly different at $P<0.05$. 


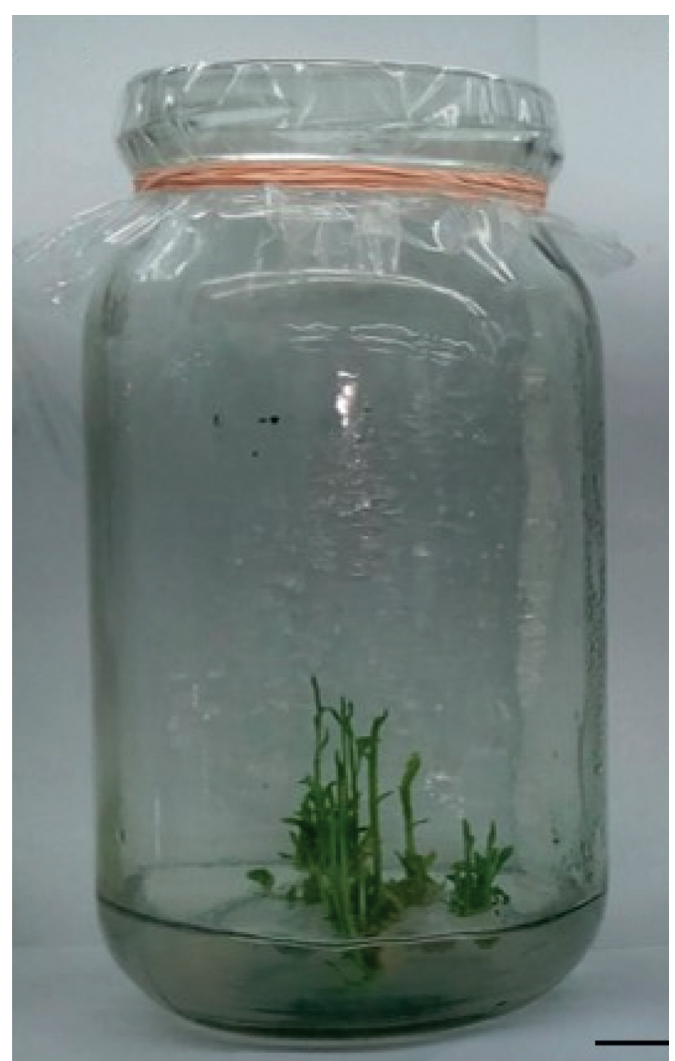

(a)

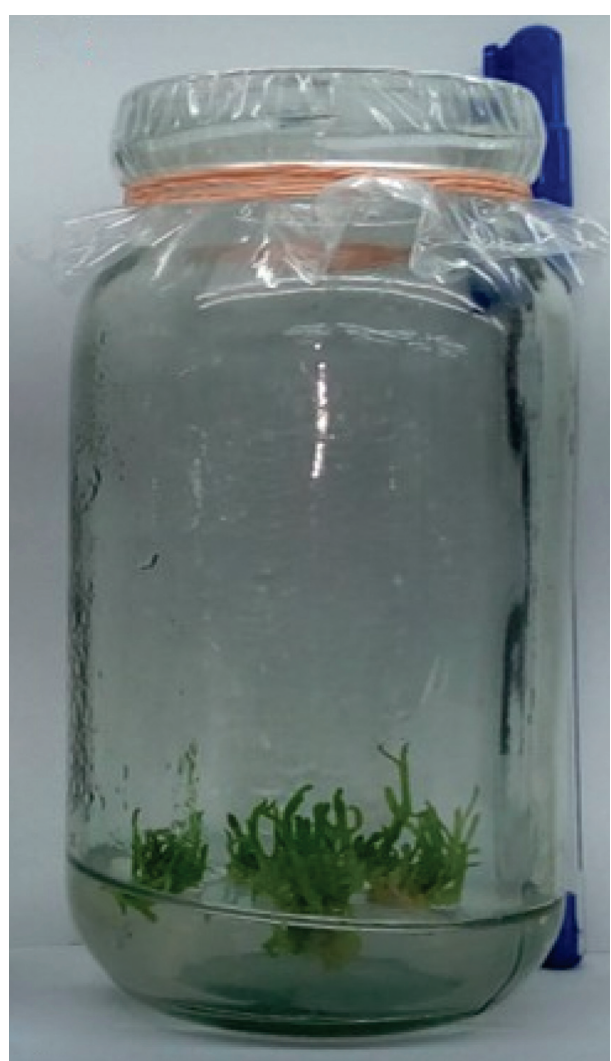

(b)

FIgURe 2: The comparison of shoot growth. (a) Full MS and (b) $1 / 2 \mathrm{MS}$ media. Scale bar, one cm.
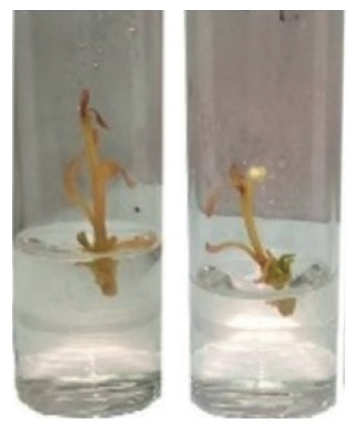

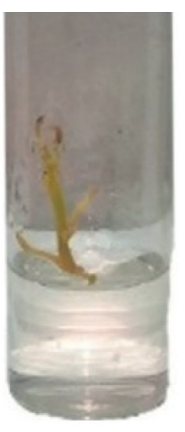

(a)
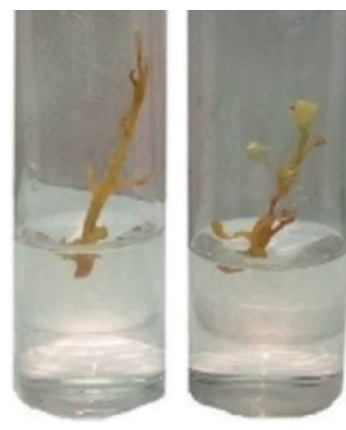

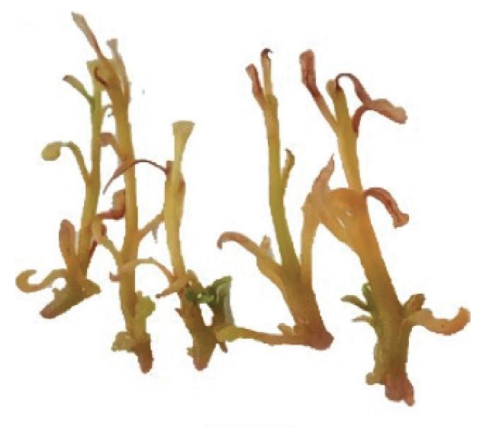

(b)

FIGURE 3: Vitrification of shoots caused by higher BAP concentrations. (a) Vitrified shoots inside the glass tubes; (b) vitrified shoots taken out from the medium. Scale bars represent one $\mathrm{cm}$ separately for panels A and B.

$1 / 2 \mathrm{MS}$ ), sugar level ( $3 \%$ and $6 \%$ ), and hormone (IBA or NAA). It was clear that NAA was capable of generating roots required for bael shoots in in vitro cultures. It also highlighted the fact that growth regulators are needed for rooting as zero hormonal applications did not produce any positive rooting results. Regarding the $\mathrm{N}$ content, either full MS or $1 / 2 \mathrm{MS}$ was fine in giving positive results; however, full MS provided more rooting success $(60 \%)$ than $1 / 2 \mathrm{MS}$, which displayed only $33 \%$ success (Figures 5(a)-5(b) and 6(a)$6(\mathrm{c}))$. The $6 \%$ sugar and $1 \mathrm{mg} / \mathrm{l}$ of NAA also produced enlarged ends in the shoot bases proving that $6 \%$ sugar level is too much for rooting of bael in in vitro cultures
(Figures 5(a)-5(b) and 6(d)). When the enlarged part was cut off and recultured, the enlargement happened once again. The $6 \%$ sugar levels also lead to the vitrification of shoots at later stages as in the shoots shown in Figure 3.

3.6. Experiment 5: Acclimatization of In Vitro-Generated Plants. The plantlets were responsive to the acclimatization treatments slowly and displayed improved tolerance to the lower relative humidity and 70\% light intensity. After two weeks, nearly $80 \%$ of the plants survived, and at the end of the four weeks, $60 \%$ of the plants survived and was ready to 
TABLE 2: The growth of shoots under BAP treatments.

\begin{tabular}{lcc}
\hline BAP $(\mathrm{mg} / \mathrm{l})$ & Mean number of shoots & Mean length of shoots $(\mathrm{cm})$ \\
\hline 0.0 & $2.00^{\mathrm{c}}$ & $2.49^{\mathrm{e}}$ \\
0.5 & $5.60^{\mathrm{a}}$ & $2.99^{\mathrm{d}}$ \\
1.0 & $6.20^{\mathrm{a}}$ & $3.83^{\mathrm{a}}$ \\
2.0 & $6.00^{\mathrm{a}}$ & $3.34^{\mathrm{b}}$ \\
4.0 & $3.40^{\mathrm{b}}$ & $3.14^{\mathrm{c}}$ \\
\hline
\end{tabular}

Within a column, means followed by the same letter are not significantly different at $P<0.05$.

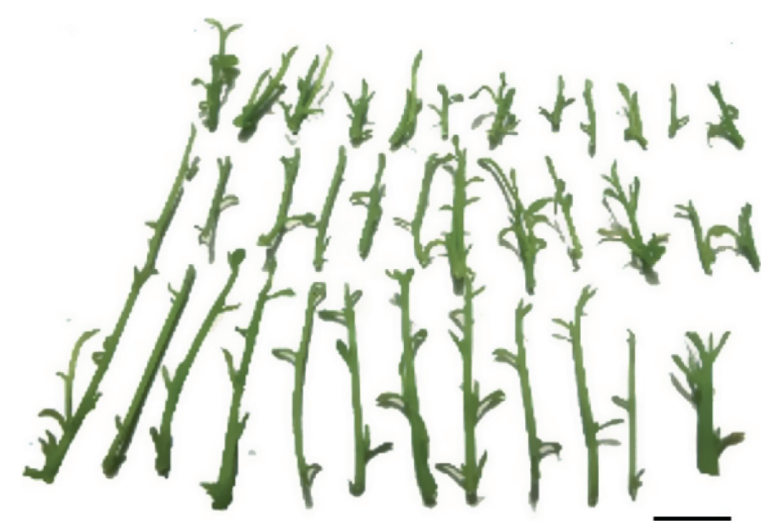

FIGURE 4: The nonvitrified shoots generated by lower BAP concentrations. The shoots are prepared for measurements and subculturing. Scale bar represents one $\mathrm{cm}$.

TABLE 3: Effect of N, hormone, and sugar levels on rooting of in vitro cultures of bael

\begin{tabular}{|c|c|c|c|}
\hline Medium composition & (\%) sugar & Hormone and concentration $(\mathrm{mg} / \mathrm{l})$ & Number of shoots produced roots (out of 20 ) \\
\hline \multirow{6}{*}{ Full MS } & \multirow{3}{*}{3} & 0 & 0 \\
\hline & & 1 NAA & 12 \\
\hline & & $1 \mathrm{IBA}$ & 0 \\
\hline & \multirow{3}{*}{6} & 0 & 0 \\
\hline & & $1 \mathrm{NAA}$ & 0 \\
\hline & & 1 IBA & 1 \\
\hline \multirow{6}{*}{$1 / 2 \mathrm{MS}$} & \multirow{3}{*}{3} & 0 & 0 \\
\hline & & 1 NAA & 6 \\
\hline & & 1 IBA & 0 \\
\hline & \multirow{3}{*}{6} & 0 & 0 \\
\hline & & $1 \mathrm{NAA}$ & 2 \\
\hline & & $1 \mathrm{IBA}$ & 1 \\
\hline
\end{tabular}

be used in planting purposes. After two months, $42 \%$ of the plants remained in the healthy condition, which is a higher value for woody perennials.

\section{Discussion}

A well-established micropropagation procedure is essential for bael if it is to be established as a country-wide cash crop [19]. The lower percentage of seed germination, the presence of miniature or aborted seeds in the fruits, and highly heterozygous nature of the species, which is leading to the segregation of traits, are making sexual reproduction ineffective. The micropropagation of bael has been tried, and results were obtained in many studies [9, 12, 13, 20]. However, we noted that in the present study, such protocols could not be directly translated to our conditions; hence, optimizations were required. Therefore, the present study possesses a paramount significance as for the first time in Sri Lanka, we have established a sound and easier protocol to clonally multiply the field-grown elite accessions of bael using leaf and twig explants.

Micropropagation techniques have been successfully employed for rapid multiplication of the superior bael using nodal segments [9], cotyledons [10-13], nodes [9], and the axillary buds [14]. The type of explant and various other conditions required for the establishment of micropropagation technique have been extensively discussed and compared in the study by Vasava et al. [19]. However, for the elite bael accessions in Sri Lanka, specific sterilization technique, hormone combination, and nitrogen content required have not been established to come up with a successful micropropagation protocol. 


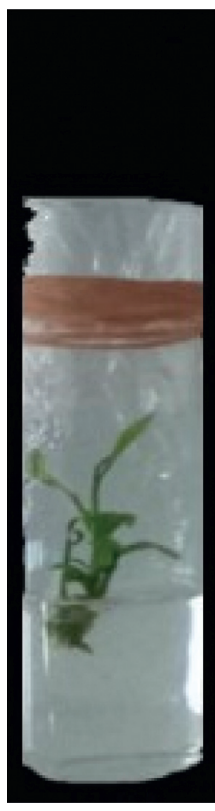

(i)

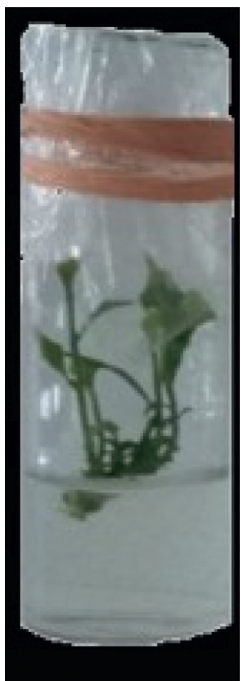

(vii)

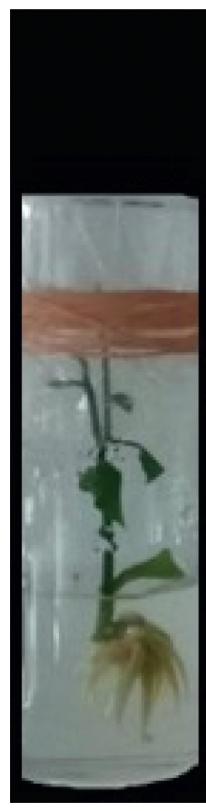

(ii)

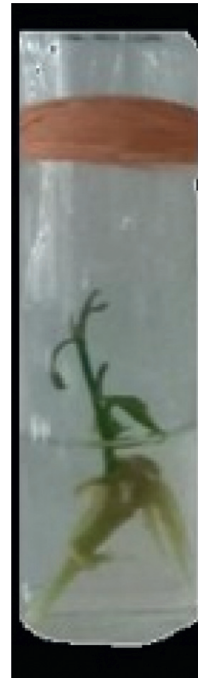

(viii)

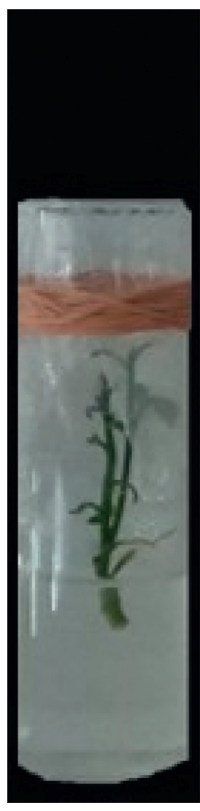

(iii)

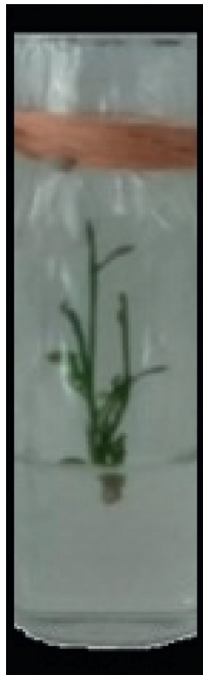

(ix)

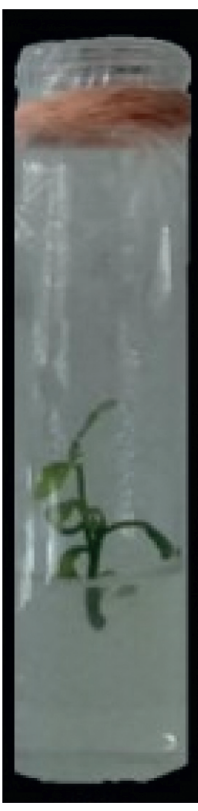

(iv)

(a)

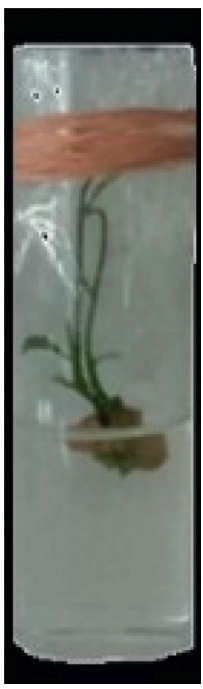

$(\mathrm{x})$

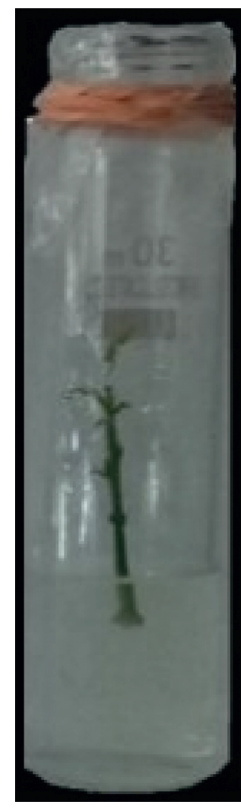

(v)

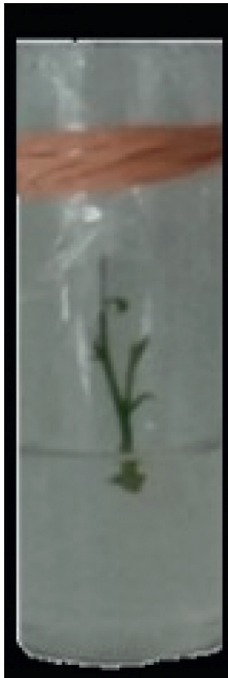

(xi)

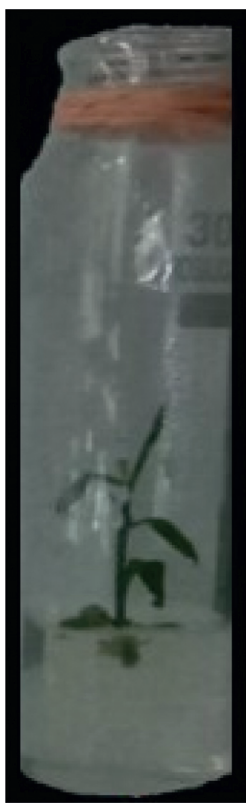

(vi)

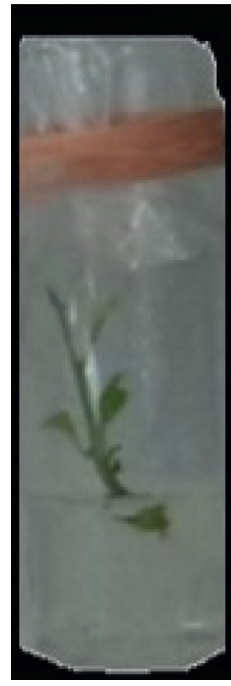

(xii)

(b)

FIGURE 5: A set of representative cultures showing the effect of $\mathrm{N}$ hormone and sugar on rooting. (a) MS (i, no hormone and 3\% sugar; ii, $1 \mathrm{mg} / \mathrm{l} \mathrm{NAA}$ and 3\% sugar; iii, $1 \mathrm{mg} / \mathrm{l} \mathrm{IBA}$ and 3\% sugar; iv, no hormone and 6\% sugar; $\mathrm{v}, 1 \mathrm{mg}$ NAA and 6\% sugar; and vi, $1 \mathrm{mg}$ IBA and 6\% sugar); (b) $1 \frac{1}{2} \mathrm{MS}$ (vii, no hormone and 3\% sugar; viii, $1 \mathrm{mg} / \mathrm{l} \mathrm{NAA}$ and $3 \%$ sugar; ix, $1 \mathrm{mg} / \mathrm{l} \mathrm{IBA}$ and $3 \%$ sugar; $\mathrm{x}$, no hormone and $6 \%$ sugar; xi, $1 \mathrm{mg}$ NAA and $6 \%$ sugar; and xii, $1 \mathrm{mg}$ IBA and $6 \%$ sugar).

The sterilization of the explants is the most challenging step in bael micropropagation. It was painstaking to carry out the necessary sterilization as the phenological growth stage of the explant always confounded the sterilization treatment. Thus, when the explants were collected from the appropriate phenological growth stage, the effect of sterilization can be studied. The results demonstrated that immersing explants in $2.5 \%$ fungicide solution for two hours provided the highest success, and that was not significantly different among leaf and twig explants. The success rate was found to be nearly $50 \%$, and it is a practically higher rate in any form of micropropagation. Thus, the fungal species might be the reason for contaminations in the early stages of the culture establishment.

To verify the presence of fungi in explants, SEM was carried out, and it was clear that before the fungicide treatment, fungal hyphae were present (Figures 1(a) and $1(c)$ ) in both surfaces of the leaves, and the fungicide treatment was able to destroy the fungal hyphae as observed in Figure 1(b) and 5.1D. However, in twig explants 


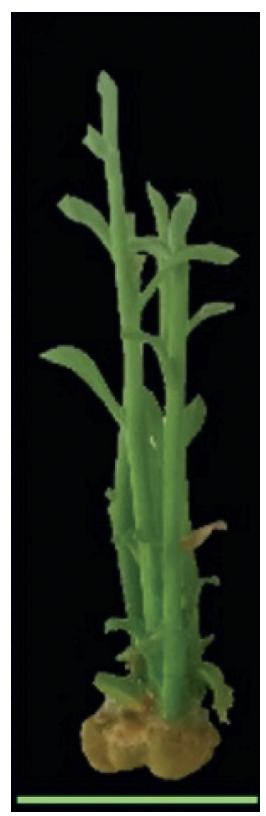

(a)

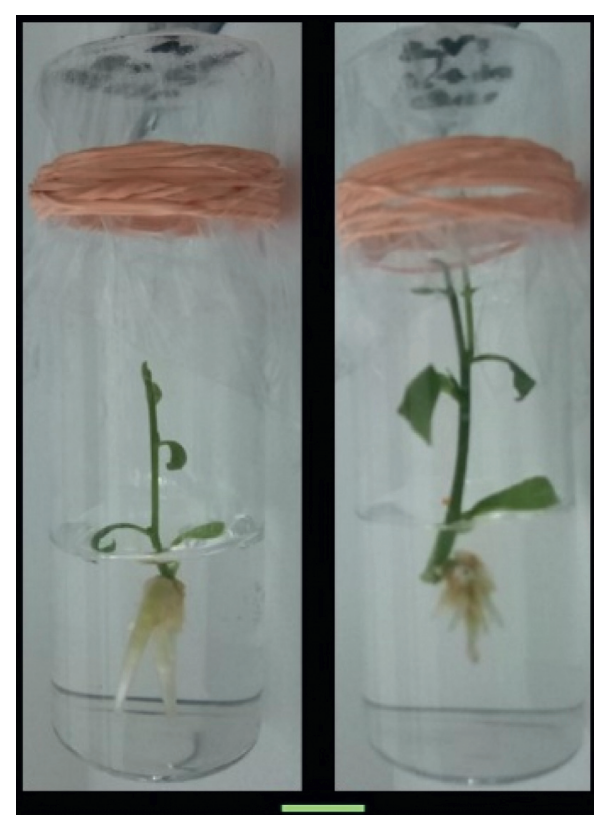

(b)

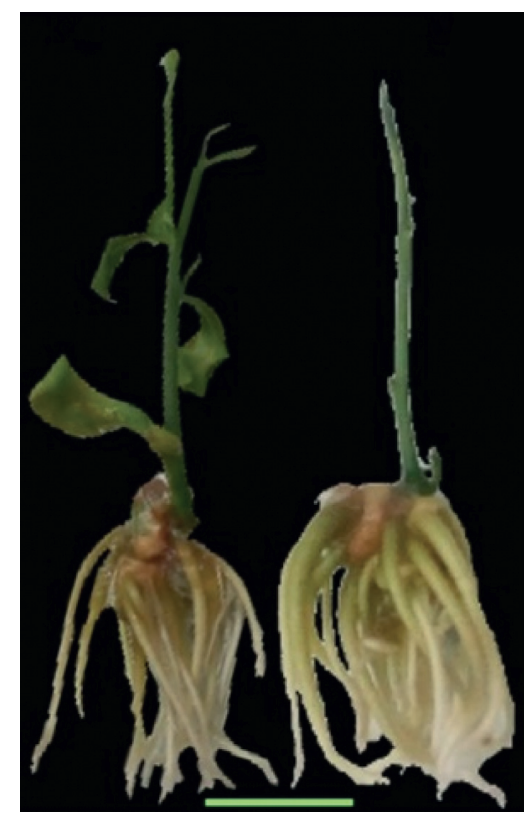

(c)

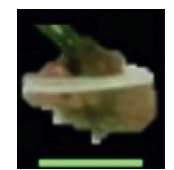

(d)

Figure 6: The rooting results. (a) Three shoots just before inserting in the rooting medium; (b) shoots form roots; (c) rooted plantlets removed for subculturing; (d) bottom enlargement observed.

examined, no apparent fungal hyphae were observed probably due to the falling off during the sample processing for SEM (Figures $1(\mathrm{e})-1(\mathrm{~h})$ ). It was also noted that bael possesses sunken stomata in both surfaces of the leaves. The stomata present in twigs are smaller than the ones present in leaves. The sunken stomata and small stomata are two significant adaptations for drought. These observations are in line with the drought-tolerant trait of the bael.

The phenological growth stage of the tree subjected to the collection of explants influences the percentage success in micropropagation [21]. Bael has marked phenological growth difference concerning the rainfall, temperature, and fruiting [22]. Rhagu et al. [21] reported that October-December is the best time to collect explants as the plant is at its best phenological stage for a higher success rate of micropropagation in Kerala, India. The phenological stage of the plants is essential for deciding the effective fruiting season and collecting the vegetative parts as planting material [23]. During flowering and fruiting of the plants, the internal hormonal profiles often hinder the effective regeneration capabilities. However, if the plant parts are taken from actively growing trees, regeneration can be achieved swiftly with higher success rates [21]. The phenology of bael is complex, and vegetative and reproductive phases are overlapped [22]. In India, the bael phenology has been correlated with success rates in the micropropagation [21]. The ideal phenological stage of bael accessions in Sri Lanka to collect explants for successful micropropagation is between April and June when there is a predominant vegetative growth [17].

The $\mathrm{N}$ content, as given by the full or $1 / 2 \mathrm{MS}$ media, has the same effect on the establishment of cultures. The full MS medium did not provide better results in terms of a higher number of shoots per cutting, taller shoots, and a higher number of leaves per shoot (Table $1 ; P>0.05$ ) than $1 / 2 \mathrm{MS}$ medium. Although both leaf and twig explants produced successful results in multiplication, the twig explants performed significantly better according to the measured parameters (Table $1 ; P<0.05$ ).

In the shooting experiment, the optimum concentration of BAP for shoot development was $1 \mathrm{mg} / \mathrm{l}$ that produces the mean highest number of shoots and the significantly mean most extended shoots (Table 2; $P<0.05$ ). The BAP concentration of $4.0 \mathrm{mg} / \mathrm{l}$ did not produce successful results and led to the vitrification of shoots, implying that too much BAP is not applicable to bael. In some other studies on bael micropropagation, NAA was used in combination with BAP; however, we wanted to make sure the appropriate development of shoots before triggering the rooting so that the attempts were made only using BAP. Bindhu [20] reported that the BAP concentration of $2 \mathrm{mg} / \mathrm{l}$ is efficient for the shooting of bael over the other combinations/concentrations of BAP/kinetin. Pati et al. [9] have obtained successful shooting for bael by applying a combination of BAP and NAA.

Full MS with $1 \mathrm{mg} / \mathrm{l}$ of NAA would provide at least 50\% success in rooting of bael shoots in in vitro cultures (Table 3 ). The comparable images display the variable success as shown in Figures 4 and 5. In a study conducted at Thrissur District, Kerala, India, indoleacetic acid (IAA) at the concentration of $0.01 \mathrm{mg} / \mathrm{l}$ was found to be effective in inducing rooting [20]. Pati et al. [9] observed successful rooting at a combination of IBA + IAA. Raghu et al. [21] obtained successful results with ex vitro rooting by adding napthoxyacetic acid (NOA) and IBA in a mix, but we did not attempt ex vitro rooting in the present study. These contrasting findings demonstrate the 
fact that the hormonal concentrations for rooting are highly specific to the given conditions.

\section{Conclusions}

The most productive sterilization method at the explant preparation stage is the washing of explants collected from the field in a $2.5 \%$ fungicide solution for two hours. Both leaf and twig explants exhibited similar success rates in undergoing direct organogenesis and axillary bud proliferation. The full MS and $1 / 2 \mathrm{MS}$ media provided the same performance in shooting. The twig plants outperformed leaf explants in terms of shoot extension, in which twig explants on average yields $1.33 \mathrm{~cm}$ taller shoots. The BAP concentration of $1 \mathrm{mg} / \mathrm{l}$ produces the highest number of shoots (6.20) and the most extended shoots $(3.83 \mathrm{~cm})$. The successful rooting was observed with full MS, $1 \mathrm{mg} / \mathrm{ml} \mathrm{NAA}$, and $3 \%$ sugar with $60 \%$ cultures compared to the other treatments employed. These results could be successfully applied in the mass production of clonal bael plants from elite accessions to establish the species bael as a profitable cash crop in Sri Lanka.

\section{Data Availability}

The data used to support the findings of this study are available from the corresponding author upon request.

\section{Disclosure}

The funders had no role in the design of the study; in the collection, analyses, or interpretation of data; in the writing of the manuscript; or in the decision to publish the results.

\section{Conflicts of Interest}

The authors declare that they have no conflicts of interest.

\section{Authors' Contributions}

C. P., T. M., and J. E. were involved in conceptualization; C. P., U. A., U. D., L. G., K. K., and J. E. were involved in methodology; C. P. was involved in data curation; L. G., K. K., and C. P. were involved in collecting plant material; C. P. was involved in writing the original draft and in visualization; C. P., T. M., and, J. E. were involved in editing, and reviewed the manuscript; T. M. and J. E. were involved in supervision and funding acquisition; and J. E. was involved in project administration. All authors have read and agreed to the published version of the manuscript.

\section{Acknowledgments}

The authors would like to thank the Department of Geology, Faculty of Science, University of Peradeniya, Sri Lanka, for kindly providing scanning electron microscope facilities. This research was funded by the National Science Foundation, Sri Lanka (research grant no. RG/2015/BT/05).

\section{References}

[1] R. Chanda, A. Ghosh, T. Mitra, J. P. Mohanty, N. Bhuyan, and G. Pawankar, "Phytochemical and pharmacological activity of Aegle marmelos as a potential medicinal plant: an overview," The Internet Journal of Pharmacology, vol. 6, no. 1, p. 3, 2008.

[2] V. K. Singhal, A. Salwan, P. Kumar, and J. Kaur, "Phenology, pollination and breeding system of Aegle marmelos (Linn.) correa (Rutaceae) from India," New Forests, vol. 42, no. 1, pp. 85-100, 2011.

[3] M. K. Seth, "Trees and their economic importance," The Botanical Review, vol. 69, no. 4, pp. 321-376, 2003.

[4] J. Benni, R. Suresha, and M. Jayanthi, "Evaluation of the antiinflammatory activity of Aegle marmelos (Bilwa) root," Indian Journal of Pharmacology, vol. 43, no. 4, pp. 393-397, 2011.

[5] M. S. Baliga, H. P. Bhat, N. Joseph, and F. Fazal, "Phytochemistry and medicinal uses of the bael fruit (Aegle marmelos Correa): a concise review," Food Research International, vol. 44, no. 7, pp. 1768-1775, 2011.

[6] J. F. Morton, Fruits of Warm Climates, Creative Resource Systems Inc, Winterville, NC, USA, 1987.

[7] S. Charoensiddhi and A. Anprung, "Bioactive componds and volatile compounds of Thai bael fruit (Aegle marmelos (Linn.) correa) as a valuable source for functional food ingredients," International Food Research Journal, vol. 15, no. 3, pp. 287295, 2008.

[8] V. B. Lambole, K. Murti, U. Kumar, B. P. Sandipkumar, and V. Gajera, "Phytopharmacological properties of Aegle marmelos as a potential medicinal tree: an overview," International Journal of Pharmaceutical Sciences Review and Research, vol. 5, no. 2, pp. 67-72, 2010.

[9] R. Pati, R. Chandra, U. K. Chauhan, M. Mishra, and N. Srivastava, "In vitro clonal propagation of bael (Aegle marmelos Corr.) CV. CISH-B1 through enhanced axillary branching," Physiology and Molecular Biology of Plants, vol. 14, no. 4, pp. 337-346, 2008.

[10] C. B. Pradeepa Devi, R. M. Gopal, and A. Settu, "Plant regeneration of Aegle marmelos (L.) corr. from cotyledon explants through In vitro studies," Journal of Natural Product and Plant Resources, vol. 4, no. 2, pp. 52-55, 2014.

[11] P. Nayak, P. R. Behera, and T. Manikkannan, "High frequency plantlet regeneration from cotyledonary node cultures of Aegle marmelos (L.) Corr." In Vitro Cellular \& Developmental Biology_Plant, vol. 43, no. 3, pp. 231-236, 2007.

[12] D. P. Prematilake, H. A. S. Nilmini, and C. Kudagamage, "Establishment of an in vitro plant regeneration system for Aegle marmelos (L.) Corr. via organogenic callus culture," Ceylon Journal of Science-Biological Science, vol. 35, no. 2, pp. 87-90, 2006.

[13] M. Hossain, R. Islam, M. R. Karim, O. I. Joarder, and B. K. Biswas, "Regeneration of plantlets from in vitro cultured cotyledons of Aegle marmelos Corr. (Rutaceae)," Scientia Horticulturae, vol. 57, no. 4, pp. 315-321, 1994.

[14] D. Ajithkumar and S. Seeni, "Rapid clonal multiplication through in vitro axillary shoot proliferation of Aegle marmelos (L.) Corr., a medicinal tree," Plant Cell Reports, vol. 17, no. 5, pp. 422-426, 1998.

[15] K. Gandhi, E. Rajesh, S. Saravanan et al., "Micropropagation of aegle marmelos L. a medicinal tree through culture of axillary bud and shoot tip explants from In vitro germinated seedlings," International Journal of Scientific Research in Biological Sciences, vol. 5, no. 3, pp. 65-71, 2018.

[16] J. P. Eeswara, T. Stuchbury, E. J. Allan, and A. J. Mordue, “A standard procedure for the micropropagation of the neem tree 
(Azadirachta indica A. Juss)," Plant Cell Reports, vol. 17, no. 3, pp. 215-219, 1998.

[17] C. K. Pathirana, A. M. U. R. K. Attanayake, D. M. U. S. K. Dissanayake et al., "Effect of phenological growth stage on establishment of In-vitro cultures of Bael (Aegle marmelos (L.) Corr.)," Tropical Agricultural Research, vol. 29 , no. 3, pp. 268-275, 2018.

[18] T. Murashig and F. Skoog, "A revised medium for rapid growth and bioassay with tobacco tissue culture," Plant Physiology, vol. 15, no. 3, pp. 473-797, 1962.

[19] D. Vasava, M. M. Kher, M. Nataraj, and J. A. Teixeira da Silva, "Bael tree (Aegle marmelos (L.) Corrêa): importance, biology, propagation, and future perspectives," Trees, vol. 32 , no. 5 , pp. 1165-1198, 2018.

[20] K. B. Bindhu, "In vitro propagation of Aegle marmelos through nodal explants," International Journal of Science and Research, vol. 4, no. 4, pp. 691-694, 2013.

[21] A. V. Raghu, S. P. Geetha, G. Martin, I. Balachandran, P. N. Ravindran, and K. V. Mohanan, "An Improved micropropagation protocol for bael-a vulnerable medicinal tree," Research Journal of Botany, vol. 2, no. 4, pp. 186-194, 2007.

[22] K. Kishore, K. K. Mahanti, and D. Samant, "Phenological growth stages of bael (Aegle marmelos) according to the extended Biologische Bundesantalt, Bundessortenamt und Chemische industrie scale," Annals of Applied Biology, vol. 170, no. 3, pp. 425-433, 2017.

[23] M. C. Salinero, P. Vela, and M. J. Sainz, "Phenological growth stages of kiwifruit (Actinidia deliciosa 'Hayward')," Scientia Horticulturae, vol. 121, no. 1, pp. 27-31, 2009. 